TẠP CHÍ KHOA HỌC ĐẠI HỌC TÂN TRÀO

ISSN: 2354 - 1431

http://tckh.daihoctantrao.edu.vn/

\title{
Hoạt động của con số trong tục ngữ Tiếng Việt
}

\author{
Hà Quang Năng ${ }^{a}$ * \\ ${ }^{a}$ Tù điển học và Bách khoa thu Việt Nam \\ *Email:nanghaquang@gmail.com
}

\section{Thông tin bài viết}

Ngày nhận bài:

25/12/2017

Ngày duyệt đăng:

$12 / 6 / 2018$

Tù khoá:

Tục ngũu, con số, hoụt động của con số trong tục ngũ.

\section{Tóm tắt}

Báo cáo dành cho việc khảo sát, miêu tả và phân tích đặc điểm hoạt động của số từ trong kho tàng tục ngữ tiếng Việt. Trên cơ sở thống kê các câu tục ngữ có chứa các số từ trong kho tàng tục ngữ tiếng Việt, xác định số lượng, tần số sử dụng của các số từ trong các câu tục ngữ, báo cáo tập trung miêu tả, phân tích hoạt động của các số từ về hai phương diện: sự kết hợp giữa các số từ trong các câu tục ngữ và khả năng kết hợp của các số từ với các từ loại danh từ, động từ và tính từ.

\section{Dẫn nhập}

Trong hệ thống từ loại tiếng Việt, "số từ là lớp từ gần gũi với danh từ ở cách gọi tên "vật", tuy nhiên "vật" ở đây là những khái niệm về số đếm chính xác và trừu tượng “ $[2,489]$. "Số từ biểu thị khái niệm nhưng khái niệm này rất đặc biệt: nó không gắn liền với sự vật thực tế cho nên số từ là phần trừu tượng nhất của từ hội. Trong câu nói số từ không phải đi kèm những từ định danh khác" $[4,20]$. "Số từ là từ loại biểu thị số lượng và thứ tự. Số từ chia thành hai tiểu loại: Số từ chỉ lượng và số từ chỉ thứ tự”. [17, 218].

Khi xem xét số từ với tư cách là một từ loại độc lập, Lê Biên [3, 138] đã chỉ ra những đặc trưng ngữ nghĩa, ngữ pháp của loại từ này.

- So với đại từ, số từ gần với thực từ hơn. Nó còn có những nét nghĩa chân thực.

- Số từ có thể làm thành tố trung tâm cho một ngữ số từ. Đặc điểm nổi bật thường thấy là số từ thường đi kèm danh từ, là thành tố phụ cho danh từ, hạn định về mặt số lượng. Số từ có tác dụng quan trọng về mặt ngữ pháp: Khả năng kết hợp với số từ là một tiêu chí để phân biệt từ loại danh từ với từ loại khác.

Các nhà ngôn ngữ học có sự phân loại không hoàn toàn đồng nhất nhưng cũng không có sự khác biệt quá rõ ràng trong cách phân loại số từ.
Trong "Ngũu pháp tiếng Việt", Diệp Quang Ban trình bày một cách tổng quát hơn về sự phân loại của số từ. Ông cho rằng số từ thường được chia thành hai lớp nhỏ: số từ số đếm và số từ thứ tự. [2, 490 - 491]

Trong tục ngữ tiếng Việt, cả số từ số đếm và số từ thứ tự đều được sử dụng. Điều đáng nói là các số từ nếu đứng một mình thì thường mang nghĩa cụ thể, nghĩa đen nhưng khi chúng kết hợp với nhau hoặc kết hợp với các từ loại khác trong câu tục ngữ lại đem đến cho chúng ta những ý nghĩa khái quát, ý nghĩa biểu trưng bất ngờ, thú vị.

\section{Tần số sử dụng của các con số trong tục ngữ tiếng Việt}

Qua khảo sát và thống kê của chúng tôi trên tổng số 4278 câu tục ngữ có mặt trong "Tục ngũu Việt Nam" [5] thì có 490 câu tục ngữ chứa con số, chiếm tỉ lệ 11,45\%. Các con số xuất hiện trong tục ngữ đa dạng và phong phú, ngoài các con số từ 1 đến 10 , các số trăm, nghìn, vạn, thì trong tục ngữ còn xuất hiện lẻ tẻ các con số $11,12,15,17,30,36,70$...Ví dụ: Bà khoe con bà tốt, đến tháng mười một bà biết con bà; Phận gái muời hai bến nước, gặp nơi trong đục may ai nấy nhò̀; Gái rẫy chồng muời lăm quan qui, trai rẫy vơ tiền phíxuống sông; Giàu ba muơi tuổi chó mùng, khó ba muoơi tuổi em đùng vội lo; Bốn chín chura qua năm ba đã tới. 
Những con số này xuất hiện với số lượng không nhiều và ý nghĩa biểu trưng không tiêu biểu nên trong phạm vi của đề tài, chúng tôi chỉ thống kê những con số có tần số xuất hiện cao, có sự kết hợp đa dạng và phong phú qua bảng sau:

\begin{tabular}{|c|c|c|c|}
\hline TT & Con số & Số lần xuất hiện & Tỉ lệ \% \\
\hline 1 & 1 & 204 & $41,63 \%$ \\
\hline 2 & 3 & 98 & $20 \%$ \\
\hline 4 & Thứ nhất, thử hai, thứ ba, thứ bốn & 62 & $12,65 \%$ \\
\hline 6 & Trăm, ngàn, vạn & 48 & $9,79 \%$ \\
\hline 5 & 10 & 41 & $8,37 \%$ \\
\hline 3 & 2 & 35 & $7,14 \%$ \\
\hline 8 & 9 & 34 & $6,94 \%$ \\
\hline 7 & 7 & 26 & $5,31 \%$ \\
\hline 9 & 8 & 16 & $3,26 \%$ \\
\hline 10 & 4 & 16 & $3,26 \%$ \\
\hline
\end{tabular}

Nhìn vào bảng trên, chúng ta nhận thấy con số " $m \hat{o} t$ " có tần số xuất hiện cao nhất trong tục ngữ: 204 câu tục ngữ, chiếm tỉ lệ 41,63\%. Con số " $m \hat{o} t$ " trong tục ngữ có sự kết hợp rất đa dạng và phong phú. Nó có thể đứng độc lập trong câu tục ngữ, cũng có thể kết hợp với các con số khác tạo thành từng cặp số với những ý nghĩa biểu trưng khác nhau.

- Số 1 kết hợp với số 1 có 47 câu tục ngữ, chiếm tỉ lệ 23,04\%. Ví dụ: Một ngôi sao, một ao uớc; Một lời nói, một bát (đọi) máu; Đi một ngày đàng, học một sàng khôn; Một chũ nên thầy, một ngày nên nghĩa; Một đêm nằm, một năm ở...

- Số 1 kết hợp với số 2 có 17 câu, chiếm tỉ lệ 8,33\%. Ví dụ: Một ngưòi thì kín, hai ngườ thì hơ; Một là vọ, hai là nợ; Một bàn tay thì đầy, hai bàn tay thì voi; Ở nhà nhất mẹ nhì con, ra đường lắm kẻ còn giòn hơn ta; Phúc chẳng hai, tai chẳng một...

- Số 1 kết hợp với số 3 có 21 câu tục ngữ, chiếm tỉ lệ 10,29\%. Ví dụ: Một con sa bằng ba con đẻ; $B a$ tháng trông cây không bằng một ngày trông quả; Một bát cơm cha bằng ba bát cơm rể; Một đời làm hại, bại hoại ba đòi ...

- Số 1 kết hợp với số "trăm", "vạn" có 19 câu, chiếm tî̉ lệ 9,31\%. Ví dụ: Một thời loạn bằng vạn thời bình; Nhất sự thuận, vạn sự lành; Cứu nhất nhân, đắc vạn phúc...

- Số "một" kết hợp với số "chín" có 11 câu, chiếm tỉ lệ 5,39\%. Ví dụ: Kẻ một quan khinh kẻ chín tiền; Một lần không chin, chin lần chẳng nên; Một đời kiện, chín đời thù...

Ngoài ra số " $m o ̣ ̂ t$ " còn kết hợp với các số khác nhur: số 4,5,6,7...Ví dụ: Trai chê vọ mất của tay không, gái chê chồng một đồng trả vốn; Một quan có giấy một quan, năm tiền không giấy mất oan năm tiền; Một con cháu ngã sáu người dung; Một lời nói dối, sám hối bảy ngày.

Tuỳ vào sự kết hợp của con số "một" với mỗi con số cụ thể mà ta có thể xác định được ý nghĩa biểu trưng của nó trong câu tục ngữ.

Con số " $b a$ " cũng xuất hiện với tần số cao trong 98 câu tục ngữ và có sự kết hợp tương đối đa dạng và phong phú với các con số khác. Cụ thể, số " $b a$ " đứng độc lập là 29 câu tục ngữ, chiếm tỉ lệ 29,59\%. Ví dụ: Con lên ba mói ra lòng mẹ; Con lên ba mẹ sa xuơng suờn; Ngày sau con tế ba bò, sao bằng lúc sống con cho lấy chồng; Vọ ba con ở chưa hết lòng chồng...

Số " $b a$ " kết hợp với số " $b a$ " có 17 câu tục ngũ, chiếm tỉ lệ 17,35\%. Ví dụ: Nguời ba đấng, của ba loài; Đứa ở ba mùa, thày chùa ba năm; Mua danh ba vạn, bán danh ba đồng; Chó ba quanh mói nằm, người ba năm mói nói...

Số " $b a$ " kết hợp với số "bảy" gồm có 15 câu tục ngữ, chiếm tỉ lệ $15,31 \%$. Ví dụ: Ba tháng con sảy, bảy tháng con sa; Đuoọc thì chia bảy chia ba, thua thì phải ngửa ngục ra mà đền; Người thì mó bảy mó ba, người thì áo rách nhu là áo toí...

Số " $b a$ " kết hợp với số "mười" có ở 5 câu tục ngữ, chiếm tỉ lệ 5,1\%. Ví dụ: Đi mười buớc xa hơn đi ba buớc lội; Ông tha nhưng bà chẳng tha, hãy còn cái lut mồng ba tháng muời; Ba tháng muời ngày hết tuần chay gái đẻ...

Số " $b a$ " kết hợp với số "hai" là 4 câu tục ngữ, chiếm tỉ lệ 4,08\%. Ví dụ: Tháng hai trồng cà, tháng ba trồng đỗ; Tưu tam trà nhị; Tháng giêng rét đài, tháng hai rét lộc, tháng ba rét nàng Bân...

Số " $b a$ " kết hợp với số "tám" xuất hiện trong 3 câu tục ngữ, chiếm tỉ lệ 3,06\%. Ví dụ: Tháng tám đói qua, tháng ba đói chết; Tháng ba mura đám, tháng tám mixa con.

Ngoài ra, số " $b a$ " còn kết hợp rải rác với các con số: 4,5,9,10,30...với tỉ lệ rất thấp. Ví dụ: Tháng $b a$ dâu trốn, tháng bốn dâu về; Tháng chin ma chà, tháng ba ma mầm; Tam nam bất phú, tứ nũ bất bần; $Đ i$ muoòi buơóc xa hơn đi ba buớc lội; Nguoòi ta thú người ta, kẻ thì tiền ruỡi người ba muooi đồng...

Trong tục ngữ, con số "hai" xuất hiện trong 35 câu tục ngữ, chiếm tỉ lệ 7,14\%; chủ yếu xuất hiện cặp đôi với số " $m o \hat{t} t$ " ở 17 câu, chiếm tỉ lệ 48,57\%. Ví dụ: Gái hơn hai, trai hơn một; Hai thóc mói đuoọc một 
gaoo; Một đống khoai, hai đống vỏ; Một đồng kiếm nát đống cỏ, hai đồng kiếm đỏ con mắt...

Ngoài ra, số "hai" kết hợp với số "hai" là 2 câu tục ngữ, chiếm tỉ lệ $5,71 \%$. Ví dụ: Mật vàng đổi lấy mật xanh, hai tay hai gậy lậy anh sông Bò̀; Một nhà hai chủ không hòa, hai vua một nuớc ắt là không yên.

Số "hai" kết hợp với số "tám" là 4 câu tục ngữ, chiếm tỉ lệ 11,43\%. Ví dụ: Gái tháng hai, trai tháng tá; Tháng tám mua trai, tháng hai mua thóc...

Số "hai" kết hợp với số " $b a$ " là 4 câu tục ngữ, chiếm tỉ lệ 11,43\%. Ví dụ: Tháng hai thiếu mất cà, tháng ba thiếu mất đỗ; Tháng hai trồng cà, tháng ba trồng đỗ...

Số "hai" kết hợp với số "bốn" là 3 câu tục ngữ, chiếm tỉ lệ 8,57\%. Ví dụ: Chim với phuợng cũng kể loài hai chân, thú với kì lân cũng kể loài bốn vó...

Số "hai" đứng độc lập là 5 câu tục ngữ, chiếm tỉ lệ 14,28\%. Ví dụ: Bên thẳng thì bên phải chùng, hai bên cùng thẳng thì cùng đứt dây; Ruốc tháng hai chẳng khai thì thối...

Một điều khác biệt rất rõ giữa tục ngữ và thành ngữ là trong thành ngữ không hề xuất hiện các số thứ tự: thú nhất, thư hai, thư ba, thú tur. Còn trong tục ngữ, các số thứ tự này lại xuất hiện với tần số tương đối lớn: 62 câu tục ngữ, chiếm tỉ lệ 12,65\%. Trong đó các tục ngữ xuất hiện với thứ tự "thư nhất - thư hai" là 37 câu, chiếm tỉ lệ 59,68\%. Ví dụ: Thú nhất vỡ đê, thú nhì giặc đến; Thú nhất sợ kẻ anh hùng, thứ nhì sợ kẻ cố cùng liều thân; Thư nhất thiên tai, thư hai hỏa hoạn; Thư nhất đau đẻ, thư nhì ngứa ghẻ đòn ghen; Thư nhất giăc pha, thứ nhì nhà cháy...

Thứ tự "thư nhất - thư hai - thứ ba" là 23 câu, chiếm tỉ lệ 37,1\%. Ví dụ: Nhất ruộng, nhì rạ, thư ba canh điè̀n; Thư nhất vọ dại trong nhà, thư nhì trâu chậm, thứ ba rựa cùn; Thư nhất thì mồ côi cha, thú nhì gánh vã, thứ ba buôn thuyền; Nhất canh trì, nhì canh viên, tam canh điền...

Thứ tự "thư nhất - thú hai - thú ba - thú bốn" là 2 câu tục ngữ, chiếm tỉ lệ 3,23\%. Ví dụ: Thư nhất thì chết mất cha, thứ nhì buôn vã, thu ba ngược đò; Nhất nuớc, nhì phân, ba cần, bốn giống.

Ở dạng kết hợp này, chúng ta thấy rõ đây là kiểu so sánh thứ bậc. Thông thường các số thứ tự xuất hiện tăng dần từ mức độ thấp đến mức độ cao theo mô hình: Nhất A nhì B hoặc Thứ nhất A, thứ nhì B, thứ $\boldsymbol{b a} \boldsymbol{C}$, thứ tur $\boldsymbol{D}$. Thành ngữ không thấy xuất hiện các trường hợp như vậy bởi "Thành ngữ giới thiệu một hình ảnh, một hiện tượng, một trạng thái, một tính cách, một thái độ (...). Còn tục ngữ thì khác hẳn, nó (...) đi đến một nhận định cụ thể, một kết luận chắc chắn, một kinh nghiệm sâu sắc, một lời khuyên răn, một bài học về tư tưởng đạo đức. Có thể nói nội dung của thành ngữ mang tính chất hiện tượng, còn nội dung của tục ngữ nói chung là mang tính chất qui luật" $[59,13]$. Chính vì thành ngữ chỉ nêu lên một hình ảnh, một hiện tượng, một trạng thái...nên không chú ý nhận xét, nêu lên thứ tự các sự vật, hiện tượng trong thế giới tự nhiên và trong đời sống con người.

Trong tục ngữ, các số tù thứ tư xuất hiện tăng dần theo trình tư phản ánh sự sắp xếp một cách logic của nguoòi Việt. Ví dụ: Nhất cận thị, nhị cận giang; Thư nhất hay chũ, thứ nhì dũ đòn; Nhất canh trì, nhì canh viên, tam canh điền; Nhất mẹ, nhì cha, thứ ba bà ngoại; Thứ nhất kinh kì, thứ nhì phố Hiến... Trong cấu trúc so sánh này, cái quan trọng hơn được nói trước, được đặt lên hàng đầu và được khẳng định ở vị trí đầu tiên qua số từ thứ tự " $m o ̂ ̣ t$ ". Như vậy, điều mà tác giả dân gian muốn nhấn mạnh là yếu tố đứng sau con số "một".

Tuy nhiên, bên cạnh những câu tục ngữ nêu thứ tự để xem xét, đánh giá thứ tự nhất, nhì, $b a$...trong kho tàng tục ngữ còn có những trường hợp số từ xuất hiện theo thứ tự, trình tự chỉ mang tính chất ước lệ. Nghĩa là, khi sử dung cách nói theo số thứ tư thi lại biểu thị quan hệ ngang bằng, nhu nhau của vấn đề cần nêu. Trong câu tục ngữ: Nhất quỷ, nhì ma, thứ ba học trò thì dụng ý của người nói ở đây chủ yếu ví học trò nghịch ngợm, tinh quái như quỉ, ma chứ không phải trong dãy liệt kê, học trò đứng sau ma và quỷ. Tương tự như vậy, câu tục ngữ: Thứ nhất vợ dại trong nhà, thứ nhì nhà dột, thú ba rựa cùn đều cho ta thấy một sự so sánh ngang bằng nhau rất thú vị, giàu ý nghĩa biểu trưng: Tất cả các hiện tuợng, sư việc được liệt kê ra sau các tù chỉ thứ tư "thứ nhất, thư hai, thư ba" đều gây cho ta cảm giác bực minh, khó chịu nhu nhau. Có thể tìm thấy rất nhiều câu kiểu như vậy trong kho tàng tục ngữ tiếng Việt. Ví dụ: Nhất một con, nhì thuốc ngon nưa điếu; Nhất vọ, nhì trờ; Thư nhất phạm phòng, thư nhì lòng lợ; Thư nhất quan sai, thứ hai nợ đòi; Thứ nhất thì chết mất cha, thứ nhì buôn vã, thư ba ngược đò... Trong những trường hợp này, sự xuất hiện của số từ không có ý nghĩa phân biệt về thứ tự, trình tự nhưng nó đóng vai trò quan trọng kết nối các vế với nhau để diễn đạt trọn vẹn một nội dung nào đó.

Trong kho tàng tục ngữ tiếng Việt, con số "trăm", "ngàn", "van" (ở đây chúng tôi gọi chung là con số 
"trăm") cũng xuất hiện với tần số khá cao: 48 câu tục ngữ, chiếm tỉ lệ 9,79\%. Sự kết hợp của con số "trăm" với các con số khác rất hạn chế. Cụ thể số "trăm" đứng độc lập là 29 câu tục ngữ, chiếm tỉ lệ $60,41 \%$. Ví dụ: Trăm đường tránh chăng khỏi số; Có của thì của trăm dò; Trăm con trai không bằng lỗ tai con gái; Trăm on không bằng hon tiền...

Số "trăm" kết hợp với số "một" có mặt trong 19 câu tục ngữ, chiếm tỉ lệ 39,58\%. Ví dụ: Trăm tội cũng vào một gông; Me đánh một trăm không bằng cha ngăm một tiếng; Trăm cái khôn dồn một cái dại; Một điều mùng, trăm điều lo lắng...

Con số "miời" trong tục ngữ cũng có tần số xuất hiện tương đối cao: 41 lần, chiếm tỉ lệ 8,37\%. Trong đó số "muời" kết hợp với số "chín" xuất hiện trong 17 câu tục ngữ, chiếm tỉ lệ 41,46\%. Ví dụ: Chín đụn muời trâu, chết cũng hai tay cắp đit; Vay chín thì ta trả muòi, hòng khi thiếu thốn có nguời cho vay; Tháng chin ăn ruooi, tháng mười ăn ruốc; Tháng chin múa ruooi, tháng тихо̀i тита та....

Số "mười” đứng độc lập có mặt ở 13 câu tục ngữ, chiếm tỉ lệ 31,7\%. Ví dụ: Cuới vọ không treo, muời heo cũng mất; Nọc nguời bằng mười nọc rắn; Phí của trời, mười đời chẳng có; Ở có nhân, muời phần chẳng khốn...

Số "mườ kết hợp với số "năm" có mặt trong 9 câu tục ngữ, chiếm tỉ lệ 21,95\%. Ví dụ: Tháng năm hơn về truớc, tháng muời được về sau; Tháng năm khua bầu, tháng muời sầu rơm; Tháng năm năm vệc, tháng muời muời viẹcc...

Số "muoờ" kết hợp với số "sáu" chỉ xuất hiện ở 1 câu tục ngữ, chiếm tỉ lệ 2,44\%: Trâu đẻ tháng sáu, vọ đẻ tháng mưòi. Số "murời" kết hợp với số "bảy" cũng chỉ có 1 câu tục ngữ, chiếm tỉ lệ 2,44\%: Yêu nhau cau bảy bổ ba, ghét nhau cau bảy bổ ra làm muời.

Số "murời" trong tục ngữ mang cả ý nghĩa thực và ý nghĩa biểu trưng. Ý nghĩa thực của con số "mmoời" chủ yếu xuất hiện trong các biến thể "tháng mười": Tháng sáu gọi cấy rào rào, tháng muò̀i lúa chín mõ rao cấm đồng; Đêm tháng năm chura nằm đã sáng, ngày tháng mưòi chura cuời đã tối; Tháng chin ăn ruooi, tháng muò̀i ăn ruốc; Tháng muời sấm rạp, tháng chạp sấm động...

Con số "bảy" xuất hiện trong 26 câu tục ngữ, chiếm tỉ lệ $5,31 \%$. Số "bảy" chủ yếu kết hợp với con số " $b a$ ": 15 câu tục ngữ, chiếm tỉ lệ $57,69 \%$. Ví dụ: Nguoòi thì mó bảy mó ba, nguời thì áo rách nhu là áo tơ; So ra mói biết béo gầy, bảy ngày ba bão biết cây cứng mềm; Mồng bảy ngâu ra, mồng ba ngâu vào; Ăn nồi bảy quăng ra, nồi ba quăng vào...

Số "bảy" đứng độc lập là 6 câu tục ngữ, chiếm tỉ lệ 23,08\%. Ví dụ: Tháng bảy kiến bò chỉ lo lại lụt; Tháng bảy heo may, chuồn chuồn bay thi bão; Lúa tháng bảy vọ chồng giãy nhau...

Số "bảy" kết hợp với số "một" chỉ xuất hiện ở 2 câu tục ngữ, chiếm tỉ lệ 7,69\%: Một lời nói dối, sám hối bảy ngày; Một chồng rẫy là bảy chồng chò̀.

Con số "chín" xuất hiện trong 34 câu tục ngữ, chiếm tỉ lệ 6,94\%. Con số "chín" chủ yếu kết hợp với con số "mười” xuất hiện ở 17 câu tục ngữ, chiếm tỉ lệ $50 \%$ và mang một ý nghĩa biểu trưng chung là số nhiều hoặc sự đầy đủ, hoàn thiện, hoàn hảo: Chín nhịn muời ăn; Cơm chắng lành canh chẳng ngon, chín đụn muời con cũng lìa; Chín đụn, còn muốn đụn nũa là mưòi.

Số "chin" kết hợp với con số "một" xuất hiện trong 11 câu tục ngữ, chiếm tỉ lệ 32,35\%: Làm đĩ chín phương để một phuơng lấy chồng; Dẫu xây chin bậc phù đồ, không bằng làm phúc cúu cho một ngươi; Một sụ (câu) nhịn là chín sự (câu) lành.

Số “chín" đứng độc lập có mặt trong 6 câu tục ngữ, chiếm tỉ lệ 17,65\%: Họ chín đòi còn hơn nguời dung; Máu loãng còn hơn nước lã, chín đời họ mẹ còn hơn người dung; Rau muống tháng chín, nàng dâu nhịn cho me chồng ăn.

Con số "tám" xuất hiện với tần số ít hơn hiều: 16 câu tục ngữ, chiếm tỉ lệ 3,26\%. Số "tám" đứng độc lập gồm có 4 câu tục ngữ, chiếm tỉ lệ $25 \%$ : Bầu dục chẳng đến bàn thứ tám, cám nhỏ chẳng đến miệng lọn sề; Ăn tám lạng, trả nửa cân.

Số "tám" kết hợp với số "hai" có mặt trong 4 câu tục ngữ, chiếm tỉ lệ 25\%: Gái tháng hai, trai tháng tám; Cá rô tháng tám chẳng dám bảo ai, cá rô tháng hai bảo ai thì bảo.

Số "tám" kết hợp với số "tám" chỉ có 2 câu tục ngữ, chiếm tỉ lệ 12,5\%; số "tám" kết hợp với số "năm" chỉ có 1 câu tục ngữ, chiếm tỉ lệ 6,25\%; số "tám” kết hợp với số "ba" có 3 câu tục ngữ, chiếm tỉ lệ 18,75\%; số "tám" kết hợp với số "muò̀i lăm" chỉ có 1 câu tục ngữ, chiếm tỉ lệ 6,25\%; số "tám" kết hợp với số "bảy" cũng chỉ có 1 câu tục ngữ, chiếm tî̉ lệ 6,25\%. Ví dụ: Tháng tám tre non làm nhà, tháng năm tre già làm lạt; Mồng tám tháng tám không mua, bỏ cày bỏ bùa mà nhổ lúa đi; Tháng tám chua qua, tháng ba đã đến.

Số "tám" xuất hiện trong tục ngữ với hai biến thể "tháng tám". Khi xuất hiện với biến thể là "tháng 
tám”, các câu tục ngữ hầu như chỉ xuất hiện với nghĩa đen, nêu lên những hiện tượng thời tiết hoặc những kinh nghiệm trong lao động sản xuất: Tháng bảy mua gãy cành trám, tháng tám nắng rám trái buơơi; Tháng tám gió may tuới đồng; Tháng tám ăn ốc trông trăng.

Con số "bốn" xuất hiện trong 16 câu tục ngữ, chiếm tỉ lệ 3,26. Số "bốn" kết hợp với số "một" có ở 3 câu tục ngữ, chiếm tỉ lệ 18,75\%: Một lần ngại tốn, bốn lần chẳng xong; Một lời trót đã nói ra, dù rằng bốn ngựa khó mà đuổi theo. Số "bốn" kết hợp với số "ba" chỉ co 1 câu tục ngữ, chiếm tỉ lệ 6,25\%: Tháng ba dâu trốn, tháng bốn dâu về.

Số "bốn" xuất hiện trong tục ngữ với 2 biến thể: tứ, tháng $t u$. Khi xuất hiện với biến thể "tháng tu", câu tục ngữ có ý nghĩa nêu lên một hiện tượng hoặc một kinh nghiệm sản xuất của cha ông ta xưa: Mura tháng tu hu đất; Tháng giêng trồng củ tù̀, tháng tu trồng củ lạ. Khi xuất hiện với biến thể "tư", câu tục ngữ thường liệt kê các hiện tượng, người hoặc địa danh được xếp loại theo tiêu chí nào đó: Tứ hải giai huynh đệ.

\section{Khả năng kết hợp của số từ trong tục ngũ}

Số từ trong tục ngữ có thể đứng ở nhiều vị trí khác nhau: Đầu câu, giữa câu hay cuối câu. Ví dụ: Một cái tóc, một cái tội; Buôn có một, bán có muời; Đòi nọ tháng ba, đốt nhà tháng tám; Hai vọ chồng son, đẻ một con thành bốn. Số từ không chỉ xuất hiện một lần mà còn có thể xuất hiện nhiều lần trong một câu tục ngũ ngắn gọn: Nhất vợ, nhì trời; Nhất duyên, nhì phận, tam phong thổ; Nhất mẹ, nhì cha thứ ba bà ngoại. Số từ trong tục ngữ không chỉ kết hợp linh hoạt với số từ tạo nên những cặp con số góp phần tạo nên nghĩa biểu trưng của tục ngữ mà nó còn có khả năng kết hợp với các từ loại khác như danh từ, động từ, tính từ.

\subsection{Khả năng kết hợp với danh tù̀}

Số từ là từ loại có khả năng kết hợp phổ biến trước danh từ. Điều này cũng thể hiện rất rõ trong tục ngữ, con số kết hợp với danh từ chiếm số lượng lớn: 383 câu tục ngữ trên tổng số 490 câu, chiếm tỷ lệ $78,16 \%$. Trong đó con số kết hợp trước danh từ là 350 câu, chiếm tỉ lệ 91,38\%. Số từ có thể kết hợp trước danh từ tổng hợp cũng như các tiểu loại khác của danh từ để hạn định ý nghĩa số lượng cho danh từ đó. Ví dụ:

Hai vọ chồng son, đẻ một con thành bốn (Danh từ tổng hợp);

Ba năm ở với ngườ đần, chẳng bằng một lúc ở gần ngườ khôn (Danh từ thời gian);
Một con tôm có chật gì sông, một cái cái lông có chật gì lố (Danh từ chỉ loại);

An tám lang, trả nửa cân (Danh từ đơn vị);

Có bệnh bái tứ phuoong, không bệnh đồng luơng không mất (Danh từ vị trí);

Năm nhón tay có ngón dài ngón ngắn (Danh từ chỉ bộ phận cơ thể người);

Một me nuôi chín muòi con; chín muò̀ con không nuôi đuợc một me (Danh từ chỉ người);

Nhất duyên, nhì phận, tam phong thổ (Danh từ trừu tượng);

Thư nhất thiên tai, thứ hai hoả hoạn (Danh từ chỉ thời tiết);

Nhất nuớc, nhì phân, tam cần, tư giống (Danh từ chỉ chất liệu);

Trăm trâu cũng một công chăn; Một chạch không đầy đồng (Danh từ chỉ động vật).

Số từ cũng có thể đứng sau danh từ nhưng với số lượng ít hơn rất nhiều: 33 câu, chiếm tỉ lệ $8,62 \%$ và thường xuất hiện trong các kết hợp có tính ổn định. Ví dụ: Trai con một thì lấy, gái con một thì đùng (chỉ xuất hiện trong trường hợp con một mà không có con hai, con ba).

Hoặc các kết hợp danh từ - số từ trong câu tục ngữ có tác dụng nhấn mạnh vào cả cụm danh từ - số từ đó. Ví dụ: Khách một chủ nhà ba; Con một chớ đi đò đầy; Đồng một của người, đồng mưòi của ta.

\subsection{Khả năng kết hợp với động tùr}

Trong tục ngữ, số từ kết hợp với động từ chiếm số lượng ít hơn rất nhiều so với khả năng kết hợp với danh từ. Trên tổng số 490 câu tục ngữ chứa con số, chỉ có 80 câu tục ngữ có sự kết hợp với động từ, chiếm tỉ lệ $16,32 \%$. Trong đó, số từ kết hợp trước động từ là 48 câu, chiếm tỉ lệ $60 \%$. Khi số từ kết hợp với động từ để nêu lên những nhận xét về cách ứng xử của con người trong xã hội hoặc nêu lên những kinh nghiệm của nhân dân trong lao động sản xuất. Ví dụ: Chín nhịn, muời ăn; Một mất mườ ngờ; Nhất choi tiên, nhì giỡn tiền; Thứ nhất leo rễ, thứ nhì trễ cành; Tháng hai trồng cà, tháng ba trồng đỗ .

Trong những kết hợp này ý nghĩa của động từ được chuyển hoá giống danh từ do khả năng kết hợp sau số từ (Trăm nghe không bằng một thấy).

Số từ đứng sau động từ xuất hiện với tần số ít hơn: 32 câu, chiếm tỉ lệ $40 \%$. Khi số từ đứng sau động từ thì ý nghĩa nhấn mạnh thường rơi vào vế sau, cái phụ 
nhiều hơn cái chính. Ví dụ: Ông thầy ăn một, bà cốt ăn hai; Của Bụt mất một đền muời, của ngườ mất muời đền môt; Me đánh một trăm không bằng cha ngăm một tiếng.

\subsection{Khả năng kết hợp với tính tù̀}

Trong tục ngũ̃, số từ cũng có khả năng kết hợp với tính từ, nhưng số lượng ít hơn nhiều so với sự kết hợp với danh từ và động từ. Theo thống kê của chúng tôi, trong tổng số 490 câu tục ngữ chứa con số thì chỉ có 24 câu tục ngữ có sự kết hợp giữa số từ và tính từ, chiếm tỉ lệ $4,9 \%$. Trong đó số từ đứng trước tính từ là 16 câu tục ngữ, chiếm tỉ lệ $66,67 \%$. Số từ đứng sau tính từ là 8 câu tục ngữ, chiếm tỉ lệ $33,33 \%$. Khi số từ đứng sau tính từ thường nêu lên sự đánh giá về đặc điểm của sự vật, đối tượng như: Dù đẹp tám vạn nghìn tu, mà không có nết cũng hư một đời.

Với kết hợp này thì ý nghĩa của số từ tương đương các phụ từ mức độ để chỉ ý nghĩa là nhiều, rất nhiều. Nếu thiếu nết thì dù rất đẹp ông cha ta cũng xem là không có giá trị. Hoặc số từ thứ tự có khả năng kết hợp với tính từ theo quan hệ đề - thuyết để đánh giá tính chất, mức độ... của sự vật, hiện tượng. Ví dụ: Nhất / cận thị, nhị / cận giang; Nhất / lé, nhì / lùn; Nhất / anh hùng, nhì / cố cùng; Nhất / cận thân, nhì / cận lân.

Qua việc khảo sát sự kết hợp của các con số với các từ loại đứng trước và sau nó, chúng tôi rút ra được những nhận xét sau:

- Cũng như trong thành ngữ, số từ trong tục ngữ có khả năng kết hợp với nhiều từ loại khác nhau. Số từ còn có thể kết hợp được với nhiều tiểu loại của một từ loại, chẳng hạn, kết hợp được với 11 tiểu loại của danh từ.

- Khi số từ kết hợp với các yếu tố khác đơn vị từ vựng khác (phần lớn là các thực từ) mà trong tục ngữ có hiện tượng chuyển hoá từ loại. Cụ thể là:

- Danh từ chỉ đồ dùng, vật dụng của nghề nông chuyển hoá thành danh từ chỉ đơn vị tính toán, đo lường như:

Chén (Thi một chén nước, phuơớc chất bằng non)

Bát (Một bát com cha bằng ba bát cơm rể; Một bát cơm rang bằng sàng com thổi)

Đọi (Một lời nói, một đọi máu)

Gánh (Một miếng lộc thánh bằng một gánh lộc trần)

Sàng (Đi một ngày đàng, học một sàng khôn)

Giành, sọt (Gái dở một giành, gái lành một sọt)

Niêu, lọ (Giàu một lọ, khó một niêu)
Nồi (Vét nồi ba mưoi cũng đầy niêu mốt)

Kho, nang (Một kho vàng bằng một nang chũ)

Thưng, đấu (Một thung cũng vào một đấu)

Nong (Một nong tằm bằng năm nong kén, một nong kèn là chín nong to')

Bồ (Nam mô một bồ dao găm).

- Động từ chỉ hoạt động tập hợp các cá thể thành một chỉnh thể chuyển hoá thành danh từ đơn vị mang ý nghĩa tập hợp như:

Nắm (Mỗi nguoòi một nắm thờ đắm đò ông)

Nạm (Một nạm gió bằng một bó chèo)

Bó, nén (Con giàu một bó, con khó một nén)

Gói (Một mếng khi đói bằng một gói khi no)

Gánh (Một gánh vàng, một nang chũ).

Như vậy, số từ có vai trò chuyển hoá một danh từ chỉ vật thành danh từ chỉ đơn vị hoặc chuyển hoá một động từ thành danh từ đơn vị. Sự chuyển hoá trên cũng thể hiện được lối tư duy dân gian chất phác, cụ thể mà biến hoá linh hoạt của người Việt.

Một điều thú vị nữa là, trong tục ngữ, để thể hiện ý nghĩa tăng tiến về số lượng, về mức độ, người ta không cần dùng các phó từ chỉ mức độ cao như: rất, quá, lắm mà sử dụng sự kết hợp giữa số từ với các danh từ chỉ đơn vị để biểu trưng cho số nhiều. Sự kết hợp như vậy đem đến những kiểu nói có vẻ phi logic nhưng lại thể hiện cách nhìn độc đáo về đối tượng. Ví dụ: Một đêm nằm, một năm ở; Một con ngựa đau, cả tàu bỏ cỏ; Một kẻ đứng đàng, cả làng nhắm mắt; Một ngôi sao, một ao uócc.

Mặt khác, số từ còn giữ một vai trò nữa là tạo khả năng kết hợp sáng tạo cho các danh từ khác, mà nhìn bề ngoài có vẻ phi logic song lại hợp lí khi người nói hướng đến một nhận thức nào đó. Ví dụ: Một nạm gió bằng một bó chèo. Trong thực tế, "nạm" không thể dùng để đo gió vì "nạm" là danh từ đơn vị chỉ một lượng vật chất rời có thể nắm bằng bàn tay. Còn "gió" là sự chuyển động của không khí. Chúng thuộc hai phạm trù khác hẳn nhau và không ai có thể lấy tay

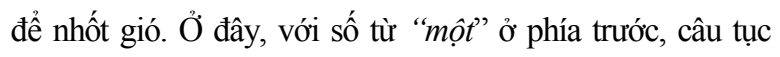
ngữ đã kết hợp được hai phạm trù ấy lại, đem đến một kinh nghiệm của nghề sông nước: Thuyền bè gặp gió sẽ thuận lọi rất nhiều với sức người bỏ ra chèo lấy.

Điều đáng nói là khi kết hợp với số từ, các yếu tố kêt hợp với nó thường mang mghĩa mới khác với nghĩa vốn có của nó, làm cho câu tục ngữ mang nghĩa để diễn đạt trọn vẹn nội dung, dụng ý của người nói. Lúc đó, số từ không còn để chỉ số lượng hay thứ tự mà mang nghĩa biểu 
trưng. Chẳng hạn, trong câu tục ngữ Một tiền gà, ba tiền thóc, khi số từ "môt $t$ " kết hợp với "tiền gă" và số từ " $b a$ " kết hợp với "tiền thóc" tạo nên cấu trúc sóng đôi thì "tiền gà" " "tiền thóc", thì tiền không còn là danh từ chỉ tiền tệ nói chung được dùng để tính toán nữa mà đã chuyển sang nghĩa khác: Tiền gà (chi phí cho việc chính), tiền thóc (chi phí cho việc phu). Nghĩa của cả câu này là: Chi phí cho việc phụ tốn kém hơn cả việc chính. Lúc này, số từ "một" và " $b a$ " không phải chỉ một số lượng cụ thể, chính xác mà nó chỉ sự đối lập giữa ít và nhiều.

Không bị hạn chế về vị trí đứng, số từ trong tục ngữ có thể kết hợp linh hoạt với nhiều từ loại, tiểu từ loại khác nhau (chủ yếu là thực từ) đem đến nhiều mô hình cấu trúc sóng đôi cân đối, hài hoà. Đặc biệt, chúng còn tạo ra nhiều kiểu kết hợp sáng tạo, mới mẻ, làm phong phú thêm kho tàng tục ngữ của người Việt. Đây là một trong những truyền thống ngữ văn tiêu biểu của người Việt xưa: U’a sự đối xứng, nhịp nhàng, thích nói cụ thể bằng những con số.

\section{Kết luận}

Từ kết quả khảo sát và miêu tả hoạt động các con số xuất hiện trong tục ngữ có thể nêu lên một số nhận xét như sau:

- Các con số xuất hiện phong phú, hoạt động của các con số trong tục ngữ là rất linh hoạt. Chúng có thể kết hợp với chính chúng hoặc các con số khác để tạo ra những cặp đối xứng. Các con số trong tục ngữ đều có thể kết hợp với các từ loại khác như danh từ, động từ, tính từ nhằm thể hiện rõ hơn hàm nghĩa được biểu hiện. Trong tục ngữ, số từ kết hợp với danh từ có tỉ lệ xuất hiện nhiều hơn sự kết hợp của chúng với động từ và tính từ, bởi lẽ danh từ dùng để gọi tên các sự vật, hiện tượng trong thực tế khách quan (mà các sự vật, hiện tượng thì vô cùng phong phú), động từ dùng để định danh hoạt động, tính từ dùng để định danh phẩm chất nên số lượng của chúng ít hơn.

- Số lượng các câu tục ngữ chứa con số khá nhiều. Tần số sử dụng, ý nghĩa biểu hiện của các con số trong thành ngữ và tục ngữ cũng khác nhau. Nếu ở thành ngữ con số "ba" - con số gắn liền với sự thiêng liêng, thần bí - là con số được ưa dùng, đặc biệt là cặp kết hợp các con số "ba" và "bảy" hay được dùng hơn cả, thì trong tục ngữ những điều nhân dân muốn khẳng định, nhấn mạnh hay gửi gắm thường rơi vào con số "một"- con số căn bản của mọi sự tiến hoá, con số khởi đầu, luôn đem lại những điều mới mẻ, tốt đẹp, đem đến sức sống mới cho mọi người.
Các con số có thể đứng độc lập hoặc có thể kết hợp với nhau thành từng cặp. Các con số trong tục ngữ đặc biệt là con số "một" tuy có sự kết hợp rất đa dạng nhưng chúng ta vẫn có thể quy về những mô hình cơ bản, thống nhất.

Các con số trong thành ngữ hầu như đều được sử dụng với ý nghĩa biểu trưng, còn trong tục ngữ, do đặc trưng phản ánh những quy luật, những kinh nghiệm về thời tiết, kinh nghiệm trong lao động sản xuất nên có một bộ phận các câu tục ngữ, con số chỉ đơn thuần mang ý nghĩa định lượng chính xác hoặc gọi tên tháng, chứ không có nghĩa biểu trưng.

Trong tục ngữ có một bộ phận các con số được sử dụng là các số thứ tự (thứ nhất, thư hai, thư ba...) với chức năng để liệt kê các sự vật hiện tượng hoặc phản ánh thứ tự đánh giá, phân loại.

\section{TÀI LIỆU THAM KHẢO}

1. Trần Gia Anh (2007), Con số dân gian, Nxb Văn hóa Sài Gòn;

2. Diệp Quang Ban (2008), Ngũ pháp tiếng Việt, Nxb GD, H;

3. Lê Biên (1999), Từ loại tiếng Việt hiện đại, $\mathrm{Nxb}$ $\mathrm{GD}, \mathrm{H}$;

4. Đỗ Hữu Châu (1962), Giáo trình Việt ngũ̃ (tập 2, từ hội học), Nxb GD, H;

5. Chu Xuân Diên (chủ biên) (1975), Tục ngũ Việt Nam, $\mathrm{Nxb}$ KHXH, H;

6. Nguyễn Thị Duyên (2007), Ý nghĩa biểu trung của hệ biểu tuợng con số trong ca dao nguoòi Việt, Luận văn thạc sĩ khoa học ngữ văn, Trường ĐHSP Hà Nội;

7. Trương Quang Đệ (2004), Con số trong đòi sống quanh $t a, \mathrm{Nxb}$ GD, $\mathrm{H}$.

8. Hoàng Văn Hành (1980), "Tục ngũ trong cách nhìn của ngũu nghĩa học", Tạp chí Ngôn ngữ, số 4, tr.59 - 63;

9. Trịnh Thu Hiền (1999), "Một nắng hai suong”, Tạp chí Ngôn ngữ và đời sống, số 4, tr.22 - 23;

10. Trịnh Đức Hiển (2009), Tri thức người Việt về tư nhiên, xã hội qua thành ngũu, tục ngũu, đề tài nghiên cứu khoa học cấp ĐHQG Hà Nội;

11. Lê Thị Hoa (2002), "Một số ví du về cách dùng hình ảnh con số trong thành ngũ các tiếng Việt, Pháp,

Nga và Anh", Thông báo khoa học, số 6, tr.100 - 105; 
12. Nguyễn Xuân Kính (1996), “Hai khuynh huoóng trong ca dao người Việt về sụ chính xác của "con số,,”, Tạp chí Văn hoá dân gian, số 3, tr.73 - 83;

13. Đỗ Thị Kim Liên (2002), "Ngữ nghĩa của kết hợp có các từ biểu tượng chỉ con số chỉ lượng "một" trong tục ngữ Việt Nam”, Tạp chí Ngôn ngũu, số 15, tr.11 - 19.

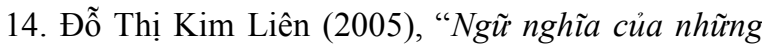
"con số” trong tho Nguyễn Bính", Tạp chí Ngôn ngũ và đời sống, số 7 , tr.13 - 17;
15. Đỗ Thị Kim Liên (2006), Tục ngũ Việt Nam duoói

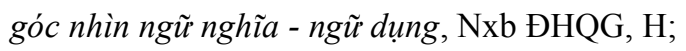

16. Nguyễn Văn Mệnh (1972), “Về ranh giới giữa tục ngũu và thành ngũu", Tạp chí Ngôn ngữ, số 3 , tr.12 - 15;

17. Nguyễn Kim Thản (1963), Nghiên cưu về ngr̃ pháp tiếng Việt (tập 1), Nxb KH, H.

\section{The activation of numerals in Vietnamese proves}

\section{Ha Quang Nang}

\section{Article info}

Recieved:

25/12/2017

Accepted:

$12 / 6 / 2018$

Keywords:

Proveb, numeral, activation of numeral in proveb.

\begin{abstract}
The paper surveys, describes and analyzes the acting characteristics of the numerals in the treasure of Vietnamese proverbs. Basing on the statistics of proverbs containing numerals in the treasure of Vietnamese proverbs, the paper determines the quantity, the frequency of usage of the numerals in proverbs. Besides that, the paper describes, analyzes the acting of numerals on two aspects: the combination between numerals in the proverbs and the ability of combination of the numerals with other parts of speech as nouns, verbs and adjectives.
\end{abstract}

